\title{
The Assessment of Renal Function Test in Perimenopausal Middle Aged Women with Hypothyroidism
}

\author{
Richa Jain ${ }^{1}$, Gaurav Gupta ${ }^{1}$, Preeti Sharma ${ }^{2}$ and Pradeep Kumar ${ }^{2}$ \\ ${ }^{1}$ Department of Biochemistry, Government Medical College, Badaun, India \\ ${ }^{2}$ Department of Biochemistry, Santosh Medical College \& Hospital, Ghaziabad, India \\ Tutor, Department of Biochemistry, Government Medical College, Badaun-243601, \\ Uttar Pradesh, India \\ *Corresponding author
}

\begin{abstract}
A B S T R A C T
The objective is to the study the Interactions between thyroid hormones and kidney functioning may coexist. The aim of this study was to investigate the renal function status in perimenopausal women with hypothyroidism. Total 60 perimenopausal women (30

Keywords

Hypothyroidism,

Perimenopause,

Creatinine

Article Info

Accepted:

20 June 2018

Available Online:

10 July 2018

cases and 30 controls) were recruited for the study. Thyroid hormones including thyroid stimulating hormone, thyroxin, and triiodothyronine were estimated by means of enzymelinked immunosorbent assay. Renal functions test including (blood urea, creatinine, uric acid, and electrolytes) were investigated by a spectrophotometric method and ion selective electrolyte respectively. Significant results were obtained in this study. There was an increased concentration of blood urea, serum creatinine and uric acid in patients with hypothyroidism when compared to control. The results were statistically significant $(<0.05)$ except urea. While in case of electrolytes there was a significantly $(<0.01)$ decreased concentration of calcium and sodium in hypothyroidism women. There was positively significant $(<0.05)$ association observed between TSH and parameters of renal function test including urea, serum creatinine and serum uric acid. Thyroid hormones play an important role in renal physiology and its functioning. The altered concentration of these hormones in patients with hypothyroidism may develop kidney disease which may progress with the progression of the disease.
\end{abstract}

\section{Introduction}

Endocrine disorders are quite common worldwide, hypothyroidism is one of them. It has been investigated that $1 \%$ to $2 \%$ people suffer from hypothyroidism (Vanderpump, 2011). In India, not an exception, its prevalence approximately $11 \%$ compared to $4.6 \%$ in the USA. Hypothyroidism is commonly affected women compared to men (Bagcchi, 2014). Hypothyroidism is a clinical disorder, laboratory investigations confirms it by presenting increased concentration of thyroid stimulating hormone (TSH) along with decreased concentration of thyroid hormones including T3 and T4 (Gupta et al., 2015). Thyroid Hormones are known to affect every organ in the body since it plays an important 
role in regulating metabolism, maintenance of water and electrolytes homeostasis, protein synthesis and influence other hormone function since these hormones are essential for normal growth and development for the kidney (Punekar, 2017; Kimmel, 2012). Any disturbance of thyroid hormones can interrupt the biochemical and physiological changes of the kidney but the mechanistic link between thyroid and kidney disease remains unclear, although animal studies have demonstrated that hypothyroidism adversely affects kidney size and structure in both development and adulthood (Mariani, 2012). So the main objective of this study was to investigate the effect of thyroid hormones on renal functions of women with hypothyroidism.

\section{Materials and Methods}

This study was carried out in Department of Biochemistry, Government Medical College, Badaun, Uttar Pradesh. The age group criteria were kept from 20 to 45 years. Total 60 perimenopausal women were recruited for the study in which 30 females were with hypothyroidism and compared with 30 normal healthy females (Martinez-Abrain, 2012). The study was approved from the institutional ethical committee.

All the participants voluntarily participated in this study and consent were taken from them. Patients having known history of diabetes mellitus, renal impairment, liver diseases, cardiovascular disease and hypertension were excluded from the study. Patients having a family history of hypothyroidism or taking medicine affecting thyroid status were also excluded from the study. Pregnant women or having last two years history of pregnancy were also excluded from the study. Only recently diagnosed hypothyroidism patients were enrolled in the study.

\section{Methods}

Estimation of Thyroid Profile: TSH, T4 and T3 were estimated by (Avantor Performance Materials, India) using Enzyme Linked Immune sorbent Assay (ELISA) (Gan et al., 2013).

Estimation of Urea: The estimation of blood urea was done by diacetyl monoxime method (Momose et al., 1965).

Estimation of Creatinine: Serum creatinine estimation was done by Jaffe's method (Husdan et al., 1968).

Estimation of Uric Acid: Uric acid estimation was also done by colourimetric method (Buchanan et al., 1965).

Estimation of Phosphate: The estimation of SPO4 was done by direct method (Daly, 1972).

Estimation of Sodium, Potassium \& Calcium: The estimation of sodium, potassium and calcium were estimated by Ion selective electrode (Albert et al., 2011).

\section{Statistical analysis}

All the baseline parameters of thyroid profile and kidney function tests were presented in Mean \pm SD. The unpaired student's t-test was used to comparing various parameters including (thyroid profile and renal function test) between the groups.

A Pearson correlation coefficient was used to the association of TSH with other parameters in patients with hypothyroidism. A p-value less than 0.05 were considered statistically significant. A statistical software SPSS (Statistical package for social sciences) was used for statistical analysis. 


\section{Results and Discussion}

All the parameters investigated in this study were statistically significant between the groups. The serum concentration of TSH and thyroid hormones both $\mathrm{T} 3$ and $\mathrm{T} 4$ were significantly different. In a patient with hypothyroidism, the level of TSH was higher while the levels of thyroid hormones were decreased. There was an increased concentration of creatinine and uric acid in case group which was significantly different from control group. While the level of urea was insignificantly increased in the case group compared to control group. In case of ions, sodium was found to be significantly different from control group while potassium was not. Sodium was significantly decreased in the case group compared to control group. The serum concentration of potassium was not significantly different between the groups (Table 1). There was positive association observed in various parameters with TSH in hypothyroidism patients. Urea, Creatinine and uric acid were positively correlated with TSH and their association was highly significant (Table 2).

Table.1 Baseline parameters between case and control groups

\begin{tabular}{|c|c|c|c|c|}
\hline S. No. & Parameters & Case & Controls & P value \\
\hline $\mathbf{1 .}$ & TSH & $7.09 \pm 3.41$ & $2.51 \pm 0.93$ & 0.000 \\
\hline $\mathbf{2 .}$ & T3 & $0.95 \pm 0.29$ & $1.15 \pm 0.21$ & 0.009 \\
\hline $\mathbf{3 .}$ & T4 & $6.61 \pm 2.48$ & $7.85 \pm 1.19$ & 0.018 \\
\hline $\mathbf{4 .}$ & Urea & $29.40 \pm 16.91$ & $25.65 \pm 4.13$ & 0.247 \\
\hline $\mathbf{5 .}$ & Creatinine & $0.97 \pm 0.29$ & $0.79 \pm 0.18$ & 0.009 \\
\hline $\mathbf{6 .}$ & Uric Acid & $6.47 \pm 1.51$ & $5.56 \pm 1.47$ & 0.022 \\
\hline $\mathbf{7 .}$ & Calcium & $9.31 \pm 0.47$ & $9.56 \pm 0.46$ & 0.022 \\
\hline $\mathbf{8 .}$ & Sodium & $133.68 \pm 4.76$ & $140.21 \pm 3.14$ & 0.000 \\
\hline $\mathbf{9 .}$ & Potassium & $4.63 \pm 0.51$ & $4.61 \pm 0.47$ & 0.883 \\
\hline
\end{tabular}

Table-2 Association of various parameters with TSH in hypothyroidism patients

\begin{tabular}{|c|c|c|c|}
\hline S. no. & Parameters & R value & P value \\
\hline $\mathbf{1 .}$ & Urea & 0.84 & 0.00 \\
\hline $\mathbf{2 .}$ & Creatinine & 0.37 & 0.04 \\
\hline $\mathbf{3 .}$ & Uric Acid & 0.72 & 0.00 \\
\hline
\end{tabular}

\#the Pearson correlation coefficient was used. A p-value $<0.05$ was statistically significant

Thyroid hormones are known to affect the kidney by systemic or local hemodynamic changes and by a direct effect on the function of this organ or mediated by cardiovascular and systemic inflammation which may influence renal functions (Van Hoek et al., 2009) in this study deranged renal functions were observed in patients with hypothyroidism. Since thyroid hormones are responsible the growth and development of the kidney; this hormone deficiency can lead to renal disorders and increased with severity of the disease. An increased concentration of blood urea in patients with hypothyroidism supported by a study from Meenakshi et al., which observed an increased concentration of urea in patients with hypothyroidism when compared with controls and it was concluded that thyroid hormones have a profuse effect on renal functions (Meenakshi et al., 2016). 
There was $33 \%$ prevalence of hyperuricemia in hypothyroidism patients since there was an increased concentration of uric acid in hypothyroidism with the positive association of TSH with uric acid due to declined renal plasma flow and urate excretion (Giordano et al., 2001). A study based on Indian population also concluded a positive association of TSH with blood urea, serum creatinine and uric acid similar to this findings (Tayal, et al., 2009). In support of this study, Vaneet et al., also observed similar findings in terms of serum urea, creatinine and uric acid in hypothyroid patients and concluded that renal function should be regularly monitored (Kaur et al., 2015).

Creatinine produced from muscle also dependent on thyroid status. In hypothyroidism, myopathy may occur, which results in enhanced release of creatinine from muscle. (Naz et al., 2014) Increased concentration of serum creatinine in patients with hypothyroidism might be the reason of decreased glomerular filtration rate due to hemodynamic changes in hypothyroidism (Karanikas et al., 2004). Additionally this increased concentration of serum creatinine might be the reason of elevated concentration of serum uric acid due to reduced levels of thyroid hormones (Jia et al., 2015). The reason behind this increase of creatinine was the influence of thyroid hormones on the tubular secretion of creatinine. In addition to this, T4 affects the $\mathrm{Na}^{+} / \mathrm{Ca}^{++}$exchanger and $\mathrm{Na}^{+} / \mathrm{K}^{+}$-ATPase activity in the kidneys by regulating transcription in sarcoplasmic reticulum (McDonough et al., 1988).Montenegro et al., concluded that greater impairment in renal functions leads to the more occurrence of hyponatremia in patients with hypothyroidism in support of this study(Montenegro et al., 1996). Although there was constant decrease and increase in the sodium and potassium level respectively along with a range of TSH in patients with hypothyroidism but screening of these ions including sodium and potassium not necessary since it is not commonly associated with hypothyroidism (Sahoo et al., 2017).

In conclusion, this study shows that patients with hypothyroidism present with deranged renal functions. The deficiency of thyroid hormones may lead to damage of the kidney which may aggravate with the severity of the disease. Persistent increase in the concentration of creatinine and urea may impair the functions of the kidney. The results conclude the kidney functions cannot be neglected during the treatment of hypothyroidism. The only limitation of this study was its sample size. So study with more sample size along with other parameters should also be conducted to establish this fact.

\section{References}

Albert V, Subramanian A, Rangarajan K, Pandey RM. 2011. Agreement of Two Different Laboratory Methods Used to Measure Electrolytes. J Lab Physicians. 3(2):104-9

Bagcchi S.2014. Hypothyroidism In India: more to be done. Lancet. 2:778

Buchanan MJ, Isdale IC, Rose BS. 1965. Serum uric acid estimation chemical and enzymatic methods compared. Ann Rheum Dis. 24:285-8.

Daly JA, Ertingshausen G.1972. Direct method for determining inorganic phosphate in serum with the "CentrifiChem". Clin Chem. 18(3):263-5.

Gan SD, Patel KR.2013. Enzyme immunoassay and enzyme-linked immunosorbent assay. J Investig Dermato 133(9):e12.

Giordano N, Santacroce C, Mattii G, Geraci S, Amendola A, Gennari C. 2001. Hyperuricemia and gout in thyroid endocrine disorder. Clin Exp Rheumatol.19(6):661-665.

Gonella Geetha Meenakshi. 2016. Renal dysfunction in hypothyroid patient's estimation of blood urea, serum creatinine, T3, T4 and TSH. International Journal of Contemporary Medical 
Research. 3(10):2915-2917.

Gupta G, Sharma P, Kumar P, Itagappa M. 2015. Study on Subclinical Hypothyroidism and its Association with Various Inflammatory Markers. J Clin Diagn Res. 9(11): BC04-BC06.

Husdan H, Rapoport A. 1968. Estimation of creatinine by the Jaffe reaction. A comparison of three methods. Clin Chem. 14(3):222-38.

Jia D, Liang LB, Tang GH, He H, Zhang M, Li ZP, Li SQ. 2015. The association between serum uric acid and creatinine in patients with hypothyroidism. Sichuan Da Xue Xue Bao Yi Xue Ban. 46(5):747-9.

Karanikas G, Schutz M, Szabo M, Becherer A, Wiesne K, Dudczak R, Kletter K. 2004. Isotopic renal function studies in severe hypothyroidism and after thyroid hormone replacement therapy. Am J Nephrol. 24(1):41-45.

Kimmel M, Braun N, Alscher M. 2012. Influence of thyroid function on different kidney function tests. Kidney blood Press Res. 35(1): 9-17

Mariani LH, Berns JS. 2012. The renal manifestations of thyroid disease. Clin $J$ Am Soc Nephrol. 23:224-26

Martinez-Abrain A. 2014. Is the ' $n=30$ rule of thumb' of ecological field studies reliable? A call for the greater attention to the variability in our data. Anim Biodiver Conserv. 37(1):95-100

McDonough AA, Brown TA, Horowitz B, et al., 1988. Thyroid hormone coordinately regulates $\mathrm{Na}+\mathrm{K}+\mathrm{ATPase} \alpha$ - and $\beta$ subunit mRNA levels in kidney. Am $J$ Physiol Cell Physiol.254(2, part 1):C323-C329.

Momose T, Ohkura Y, Tomita J.1965.
Determination of urea in blood and urine with diacetyl monoxime-glucuronolactone reagent. Clin Chem. 11:113-21.

Montenegro J, Gonzalez O, Saracho R, Aguirre R, Gonzalez O, Martinez I. 1996. Changes in renal function in primary hypothyroidism. Am $J$ Kidney Dis. 27(2):195-8

Naz A, Issa M. 2014. Rhabdomyolysis and Acute Renal Impairment in a Patient with Hypothyroidism: A Case Report. Case Rep Med. 2014:139170.

Punekar J, Singh AA, Malav MK. 2017. Study of thyroid function in patients with chronic kidney disease. Int $J$ Health $S c i$ Res.7(2):68-72

Sahoo S, Patel S, Ganguly A, Nanda R, Mohapatra E. 2017. Thyroid dysfunctions and renal status: implications in hyponatremia. Asian Journal of Medical Sciences. 8(4):6-10

Tayal D, Chawla R, Arora S, Gupta VK, Sohi JS, Mallika V. 2009 july. Dynamic Changes in Biochemical Markers of Renal Function with Thyroid Status - A Study in Indian Population. Internet Journal of Medical Update. 4(2):36-41

Van Hoek I, Daminet S. 2009. Interactions between thyroid and kidney function in pathological conditions of these organ systems: a review. Gen Comp Endocrinol. 160(3):205-215.

Vanderpump MPJ.2011.The epidemiology of thyroid disease. $\mathrm{Br}$ Med Bull. 99(1):3951.

Vaneet Kaur, Kamaljit Singh and Minni Verma. 2015. Changes in biochemical markers of renal function in subclinical and overt hypothyroidism, Int $J$ Bioassays. 4(04):3799-802.

\section{How to cite this article:}

Richa Jain, Gaurav Gupta, Preeti Sharma, Pradeep Kumar. 2018. The Assessment of Renal Function Test in Perimenopausal Middle Aged Women with Hypothyroidism Int.J.Curr.Microbiol.App.Sci. 7(07): 2641-2645. doi: https://doi.org/10.20546/ijcmas.2018.707.310 